\title{
Vocabulary Teaching Methods for Beginners and Intermediate Level Students in TCSL
}

\author{
Wenjie Dai \\ Qingdao University of Science and Technology, Qingdao, China \\ Email: cherrydai007@126.com
}

\begin{abstract}
This paper puts forward the importance and necessity of vocabulary teaching in TCSL and the methods of teaching Chinese characters and words to international students of elementary and intermediate levels. This paper consists of four parts: introduction, importance and necessity of teaching Chinese characters and words in Teaching Chinese as a Second Language (TCSL), methods of teaching Chinese characters and words to international students, conclusion and implications.
\end{abstract}

Index Terms - Chinese characters and words, teaching method, TCSL

\section{INTRODUCTION}

Along with the globalization of the world and the increasing influence of China, more and more people are attracted by Chinese language and Chinese culture. Nowadays, there are more than 40 million foreigners studying Chinese all over the world and more than 200 thousand international students studying Chinese in China. Hence the global Chinese language fever.

However, learning the square-block Chinese characters is not an easy thing, especially for those European and American students. Some students think that Chinese characters are the most difficult part in learning the Chinese language. They feel frustrated even desperate. Some of them choose to give up the learning of characters and study Pinyin only.

There are two reasons that make learning Chinese characters difficult. Objectively, Chinese characters are the only existing morpheme language in the world, which does not share any similarities with other major languages in the world. The function of a written language is to record a language. However, the language elements of recording different written languages may differ. The majority of phonetic languages need only tens of letters to record the phonemes or syllables of it. As to the Chinese language, there must be thousands upon thousands of characters to record the language elements. There are various strokes radicals and parts in the Chinese language which contribute to the difficulty of learning this language. Subjectively, when Chinese is taught as a second or foreign language, the lack of a systematic sum-up of Chinese character system and word formation law may lead to inadequate teaching, which undoubtedly magnifies the difficulty of Chinese learning.

Many scholars and TCSL teachers have done much work on the teaching methods and strategies of teaching Chinese as a second language (TCSL). And articles focusing on this question can be seen in various periodicals. Lu Jianji (1987) has made an error analysis of Chinese words and expressions for foreigners, which analyzed the main causes of word errors made by L2 Chinese language learners. He Fengqiao (1998) argues that "Attention Should Be Paid to Vocabulary Teaching" (p.82-93). Hu Mingyang (2000) has discussed "Some Questions in Vocabulary Teaching in TCSL" (p.291), mainly discussed the teaching strategies in different stages (elementary, intermediate and advanced levels). Li Rulong \& Yang Jichun (2004) holds that "Vocabulary Teaching Should Be the Focus of Teaching Chinese as a Second Language" (p.21-29). Guo Rui (2010). has introduced the idea of "Concept Map "(p.23) in teaching Chinese words to mid-level learners

All these are good attempts to enlarge the students' vocabulary and to improve the teaching efficiency, yet these papers are either too abstract to instruct the teaching activity or too complicated to operate. So the teaching methods of vocabulary in TCSL should be given serious reflection and it is also worthwhile to explore the methods and strategies to enlarge the students' vocabulary.

\section{IMPORTANCE AND NECESSITY OF TEACHING CHINESE CHARACTERS AND WORDS IN TCSL}

More and more second language acquisition researchers have reached a consensus on the importance of vocabulary in language acquisition. We all know that without grammar very little can be conveyed, yet without vocabulary almost nothing can be conveyed. According to Vermeer (1992), "knowing words is the key to understanding and being understood. The bulk of learning a new language consists of learning new words. Grammatical knowledge does not make for great proficiency in a language." (p.147)

Also, many studies conducted by linguists "have shown that L2 students think a lack of vocabulary is one of their major problems in using the language" (Simensen, 1988, p.22). It's true that the Chinese characters are regarded as the 
biggest barrier for international students to learn the Chinese language. Yet the charm of Chinese characters lies in its form. To many westerners, Chinese characters themselves exude the charm of Chinese culture.

A Chinese word can incorporate its pronunciation, meaning and grammar into its pragmatic and cultural dimensions.

As it is the case in every nation, writing transcends time and space. Chinese language differs from other ones in that the latter can be easily understood through pronunciation. Since China is such a vast country with poor accessibility that dialects often fail to get across regions. Hence the Chinese people have to turn to another method of communication: drawing. A piece of drawing is static, but when two are put together, it will appear vivid. Hence the invention of associative compounds whose form gives hints to the meaning rather than the pronunciation. This is a breakthrough in the history of cognition. Through pictographs and association, Chinese characters convey abstract meanings. They allow full rein of imagination, thereby facilitating interpersonal communication. But if approached inappropriately, Chinese characters can appear very "frightening", leading to the misunderstanding that Chinese is difficult. This misconception happens due to our insufficient introduction.

If an international student wants to learn the Chinese language well without the knowledge of the Chinese characters, he will definitely find it a mission impossible. This unique language and its culture cannot be learned or taught without a deep and correct understanding of its characters and words first.

\section{Teaching Methods of Chinese Characters AND WordS}

As it is mentioned above, Chinese language is such a special language that it needs different teaching methods to meet the various needs of learners. And all the methods should follow one principle: Characters first.

Joel Bellassen, the first Inspector of Chinese Language Teaching in France, advocates the "Character-based" methodology. He is the editor-in-chief of over ten monographs and author of more than 60 academic papers. Among them are: A Guide to Chinese Grammar, The Ideogram Empire of Chinese Characters, and Chinese Recycled. Certainly his "Character-based" methodology finds its way into all his works.

The author of this article also holds that characters should be considered first in teaching Chinese words to international students, esp. for beginners and intermediate level students.

To master the Chinese characters, one must learn the strokes first. Chinese characters have complex structures, but if they are disintegrated, some basic strokes-the minimum components, will be exposed. Mastering how to write the basic strokes is a necessary step before being able to write correct and beautiful characters. Generally speaking, there are 8 basic strokes, i.e. 点（diăn）、横（héng）、坚（shù）、敉（piě）、捺（nà）、提（té）、钩（gōu）、折（zhé） and 23 compound strokes. Strokes of different fonts may change dramatically. Individual's writing habits also determine different shapes of strokes. But deviation is not allowed in writing the key segment of a character, for a slight change of stroke shape may end up with different or wrongly written characters.

The structural units of Chinese characters include stroke, part and component. For example, “人”(rén: human, person) is made of a Piě and a Nà. Structurally, Chinese characters can be divided into two kinds: single-part characters and compound characters.

Single-part characters contain just one integral, independent part which is difficult to be disintegrated, such as “半”(bàn: half), “里”(lî:: inside), “书”(shū: book), “日”(rì: the Sun), “田”(tián: field), and so on.

For most single-part characters, they are both characters and components or parts of compound characters. So students should keep these characters in their mind.

The majority of Chinese characters are compound characters which account for about $86 \%$ of all the Chinese characters, on which we need to focus our attention. There are mainly two structure patterns: left-and right structure(e.g. 海洋) and up-and-down structure (e.g.志态). Besides, there are half-enclosure structure (e.g. 远近), enclosure structure (e.g. 圆圈) and some special structure like “品”. Most compound characters are made up of two or three parts. Components (偏旁) refer to some frequently used parts in Chinese characters to identify the certain part of a compound character. Components indicating something in common in a group of characters is called radical(部首). According to the 6th edition of Contemporary Chinese Dictionary published by the Commercial Press in 2012, there are 201 radicals in all. Since each compound character is a combination of shape, sound and meaning, TCSL teachers should study the rules of character and word formation and try to give the international students a sufficient introduction of the typical radical characters, isomorphic component characters and homophonic component characters to help them understand the phonetic and ideographic structure of Chinese characters. $※ ※ ※$ For example, the part “口”(a single-part character as well, which means "the mouth")is usually on the left side of a character, but in a small number of characters it takes the upper or lower position. It is one of the radicals with which a large number of characters are formed. It is related to acts of mouth. Verbs like 吃 (chī:eat), 喝 (hē:drink), 叫 (jiào:shout,cry), 吹 (chūi:blow), 唱 (chàng:sing), 喊 (hăn:shout), 吵 (chăo:quarrel), 吐 (tù:spit,vomit), 叹 (tàn:sigh), 哭 (kū:cry,weep), 品(p̌̌n:taste,sample)etc. all have something to do with the mouth. Another part “目”, like “口”, is also a single-part character, which means “the eye". When as a part, “目” is often on the left side of a character, but occasionally it might appear in other places. Characters with it are usually related to eyes, e.g. 眼(yăn:eye),睛(jīng:eye), 眉(méi:eyebrow), 看 (kàn:look,see), 瞧 (qiáo:look,see), 眨 (zhă:wink), 眯 (mīinarrow one’s eyes), 睡 (shuì:sleep), 眠 (miăn:sleep), 盲 (máng:blind), 瞎 
(xiā:blind),etc. Sometimes, different places of the same part may indicate different origins. Take the part “月”as an example. When used as a single-part character, it usually has something to do with the Moon or time, which means "the Moon"or"month". When used as a part of a compound character, it appear frequently on the left side and sometimes on the right side or the lower part of a character. Those with the radical on the left or the lower part have something to do with human body, e.g. 脸(liăn:face), 脖(bó:neck), 肚(dù:belly,stomache), 腿(tuǐ:leg), 脚(jiǎo:foot), 肝(gān:liver), 肺 (fèi:lung), 肩 (jiān:shoulder), 背(bèi:back), 胃(wèi:stomache),etc. Others with the radical on the right usually have something to do with the Moon or a period of time, e.g. 期(qī:date), 朝(zhāo:morning) and another pronunciation 朝 (cháo:dynasty). Yet sometimes there might be some exeptions, the word “朦胧” indicates the moonlight is dim or hazy, and the two characters can not be used as two independent words.

There are so many strokes, radicals and components in the Chinese language. Some of them are different but may look alike. If the students don't pay attention to the subtle differences between similar characters, chances are they will make a fool of themselves. And such kind of mistakes did happen. Some students often confuse the word “包子 bāozi” (a kind of Chinese food) with the word"句子 jùzi" which means "sentence". Some can not tell the difference of “午” (noon) and “牛”(ox, cow), so sometimes you'll hear or see the word “午奶”, which should be the word “牛奶”(milk). Once I asked my foreign students to speak out a sentence using the following sentence pattern:

昨天我去了 (Yesterday I went to .)

They were expected to give a noun indicating a place using the words they have just learned. Some one went to the library, someone went to the dining hall. Some went to a restaurant and some went to the seaside. Then suddenly I heard an Australian student said loudly “昨天我去了大便馆。”I asked him to repeat the sentence, hoping he can realize the mistake and correct it by himself. Yet he didn't. After I wrote the two words on the blackboard, all the students burst out laughing. Because the word “馆”indicates a place and the word “大便” means “stool”. How could he think of such a nasty place? Actually he meant to go to the “大使馆”(embassy). He just confuse the word “大便” with the word “大使” (ambassador).

To avoid such mistakes, students should be reminded to pay attention to each stroke and each part of a character.

There are 3500 commonly used Chinese characters. According to the Syllabus of Chinese Characters for HSK (Chinese Proficiency Test), there are 2905 Chinese characters (800 A-level characters, 804 B-level characters , 500+11 C-level characters and $2864+41$ D-level characters) for non-native speakers of the Chinese language to grasp according to different needs and requirements. Take the A-level characters as an example, there are 137 single-part characters and 663 compound characters. After teaching the students a certain number of .basic components, radicals, single-part characters, the students will be able to memorize more through the following methods, which enables the students to remember characters in shorter time, yet keep them in mind longer.

1. Analyze Chinese characters according to their building rules to help the students memorize new words.

Almost all the Chinese characters were originally invented on the basis of some rules, which, if known, help the students a lot to make associations. A combination of two or more characters makes a new character, whose meaning is usually determined by the meanings of its parts. Due to the incessant alteration of Chinese characters over thousands of years, especially the simplified characters since last century on the mainland, lots of characters could hardly be explained according to the rules by which they were originally invented. However, there are still a lot of characters in which the rules can be traced. Students can use their association to relieve the burden of hard work. For instance, the character "看” (kàn: look, see) has a hand (the upper part 手) over an eye (the lower part 目) which denotes looking at something far away with a hand above eyes o keep from the glare of the sunlight. “木” in ancient Chinese means “tree”, so we can imagine a man who is tired or even exhausted after work is leaning against a tree to have a rest. “目”indicates the eye while the often used radical "シ " (sāndiănshuǐ) denotes water. So we can guess the meaning of the character“泪”, which means tears (water from the eyes). A mouth “口”with a bird”鸟” together make up a new character “鸣”which means the birds sing. The traditional Chinese pen “笔” is a brush made of bamboo and animal fur to write the Chinese calligraphy. That's why it is made up of “竹” (bamboo ) and "毛” (fur).

Examples like these are numerous. As long as the students have a good command of the basic knowledge of the various kinds of parts, they will soon recognize a tremendous amount of new characters and words.

2. Analyze and classify the different components in idea-sound characters to help students compare similar characters and words.

As we have mentioned above, the majority of Chinese characters are compound-part characters. Of the compound-part characters, the majority of them are idea-sound characters, also called pictophonetic characters, which are made up of two components with one indicating idea (meaning) and the other indicating sound (pronunciation). For example, with regard to “们”, “个 ”indicates man or people, and “门” indicates the sound. Hence “们” is a plural form only for people, like “我们” (we, us ), “你们” (you ), “他们” (they, them), “咱们” (we, us), “人们” (people), 学生们 (students). But wen can not say “桌子们”（books）, ”椅子们”(chairs) because they are not human being. The three characters “铜、茼、桐” all have the same pronunciation “tóng” because they have the same sound part “同”, yet they differ in meanings because they have different idea parts. “全” (originally “金”) indicates metal, “十”证dicates 
grass or herb, and “木” means tree. So the three characters refer to a kind of metal (bronze), a kind of vegetable (crowndaisy) and a kind of tree (phoenix tree) respectively. Similarly, if we know the character “忘, 亡, 忙, 芒”, we can guess the pronunciation of the new character “盲” (máng) because they share the same part “亡”, though their initials(consonants) might differ, their finals(vowels) are often the same .

“娈” as a variant of “衣”, tells us characters having this radical all have something to do with clothes. For example, 衬衫( shirt), 袖( sleeve), 袜(socks), 被(quilt), 裤(pants, trousers ), 补( to mend ), etc. .

3. Tell the difference of characters by comparing their different parts.

International students often confuse similar characters in shape. But actually they are different. For example, “休”means a man leaning against a tree to have a rest while“体” means human body. If they know the different meanings of “日”(the Sun) and “目”(the eye), they can easily tell the difference of “晴” and “睛”.Obviously, the first means "fine(weather)" while the latter means "pupil (of the eye)".

After being taught the above mentioned methods, the international students will get "the sense of Chinese language" through learning the law of Chinese characters and build a solid foundation for further studies with the progressive order of characters $\rightarrow$ words $\rightarrow$ sentences $\rightarrow$ texts.

Based on the "characters first principle", there are some useful methods worth discussing.

4. Making good use of simple drawings

For language teaching, teachers often use pictures, photographs and objects for beginners. And these things prove to be very vivid and direct for beginners. But due to the special characteristic of Chinese characters, simple drawings might be more efficient in that the earliest Chinese characters came from drawing. Later the lines of the paintings became strokes and then we see the square-block characters. This method is very useful in teaching the objects in the nature to the students, like the mountain, rain, water, tree, the Sun, the Moon, and so forth. This method can tell the students how the objects in the nature turned into pictures and then changed into characters and give them a deep impression of the character-forming methods of pictographic and associative.

5. Adopting an "old" language teaching method: Total Physical Response (TPR)

Total Physical Response (TPR) is a language teaching method built around the coordination of speech and action. It attempts to teach language through physical (motor) activity. Developed by James Asher, it draws on several traditions, including developmental psychology, learning theory, and humanistic pedagogy, as well as on language teaching procedures proposed by Harold and Dorothy Palmer in 1925. When heard of TPR, many people will think of children's acquisition and children's acquisition only. The idea of using this method to international students (usually adults) in TCSL sounds childish, naïve or even ridiculous to some Chinese teachers. They are used to teaching in a serious atmosphere and they are used to a quiet class like giving lessons to the Chinese students. Yet Asher sees successful adult second language learning as a parallel process to child first language acquisition in a developmental sense. He feels that adults should recapitulate the processes by which children acquire their mother tongue. This method is quite useful when teaching verbs to students, especially those that are similar in meaning but not quite the same. For example, there are a group of verbs which share the same radical “提手”, which indicates an act conducted by one’s hand, “推, 拉, 拽, 拖, 提, 托, 拿, 按, 拔, 抬...” These verbs are hard to explain in foreign languages yet easier to be understood by acting out. Though easy to understand, they are difficult to memorize. But if the students are ordered to do the above acts again and again until they are familiar to these verbs, they will keep these words in their mind .This so-called out-of-date teaching method is not only suitable for children ,but also beneficial to adult learners.

6. Taking advantage of cultural experience activities to facilitate vocabulary learning as well as acculturation

"When in Rome, do as the Romans do" is a typical process of acculturation. To learn a language well, one must know something about the target language. According to Schumamm(1978a:29), in L2 acquisition , acculturation refers to "the social and psychological integration of the learner with the target language (TL) group". As a model of L2 acquisition, acculturation is the general process which involves modification of attitudes, knowledge and behavior. The whole process demands both social and psychological adaptation as well as learning the appropriate linguistic habits to function within the target language group. Actually this is the best way of learning a foreign or second language. While studying in China, why not make use of the precious chance? Besides, due to the differences between the learner's native language and the target language, there must be the missing of equivalence, i.e. things that can not be found in another language. "When in China, do as the Chinese do" is kind of a short-cut to learning Chinese vocabulary which do not have an equivalence in the students' native language. For instance, the tea ceremony, making Chinese dumplings, playing traditional Chinese musical instruments, performing Chinese Kungfu (martial arts) like Taijiquan, learning Chinese calligraphy, Chinese painting and paper cutting, celebrating traditional Chinese festivals, and so on. These experience activities will definitely give the international students a good opportunity for acculturation , and help them learn some related new words at the same time. For instance, while enjoying the tea ceremony in a teahouse, they can learn the new words “茶艺（cháyì）”which means “the tea ceremony” and “茶馆(cháguăn)”which means the teahouse. While watching the process of this, they can also learn the words “茶壸 (teapot)”“茶杯 (tea cup)”, “茶匙( tea spoon)” “红茶 (black tea)”, “绿茶 (green tea)”, “花茶 ( scented tea like jasmine flower tea, chrysanthemum tea)” and a very special verb which comes from the taste of tea “品”. By practicing Chinese calligraphy, they can get a deep impression of the strokes, radicals and components as well as the writing order. By eating the round moon-cake under the beautiful 
moonlight while appreciating the full moon on the Mid-autumn Day, the international students will have a better understanding of the relationship between the shape of the food and the connotation of family reunion.

\section{CONCLUSION AND IMPLiCATION FOR CHINESE VocABUlary TEACHING AND LEARNiNG}

We have talked several methods of teaching Chinese Characters and words which will benefit the teaching practice and learning efficiency. Yet they can not meet all the needs of the international students and their teachers. Students of different language levels and different backgrounds should be treated respectively .So the teachers should use different methods and strategies according to the actual situation. They are expected to use flexible methods to help the students enlarge their vocabulary and improve their learning efficiency. Students are also encouraged to explore different learning strategies to find out the most effective ones for themselves.

Nevertheless, there are still many questions remain to be solved. For example, all we talked about are modern Chinese and simplified Chinese characters, they definitely differ from ancient Chinese in many aspects, and the simplified characters used on the mainland are different from those in Taiwan, Hongkong, Macau and some other places among overseas Chinese all over the world. Should we take this into account? How can we do that? Shall we give out all the meanings of a word or character in the word list? Almost each Chinese character has its cultural meaning, how much and at what level shall we tell the students?

To improve the teaching and learning effects, to enlarge the students' vocabulary, both the teachers and the students have a long way to go.

\section{REFERENCES}

[1] David Nunan. (2001). Second Language Teaching and Learning. Beijing: Foreign Language Teaching and Research Press.

[2] Guo Rui. (2010). On the Strategy of "Concept Map" in Teaching of Mid-level Chinese Vocabulary. Language Teaching and Linguistic Studies.3, 23-28.

[3] He Fengqiao. (1998). Attention Should Be Paid to Vocabulary Teaching. A Collection of Papers on Teaching Chinese as a Second Language. Shanghai: Shanghai Foreign Language Education Press. 82-93.

[4] Hu Mingyang (1997). Some Questions of Vocabulary Teaching in Teaching Chinese as a Second Language. Applied Linguistics. 1, 14-19.

[5] Jack C. Richards, Theodore S. Rodgers. (2000). Approaches and Methods in Language Teaching. Beijing: Foreign Language Teaching and Research Press. London: Cambridge University Press.

[6] Li Rulong, Yang Jichun. (2004). Vocabulary Teaching Should Be the Focus of Teaching Chinese as a Second Language. Journal of College of Chinese Language and Culture of Jinan University. 4, 21-29.

[7] Lu Jianji. (1987). An Analysis of Errors in Foreigners' Study of Chinese Words and Expressions. Language Teaching and Linguistic Studies. 4, 124-134.

[8] Simensen A. M. (1998). Teaching a Foreign Language: Principles and Procedures. Bergen: Fagbokforlaget.

[9] Vermeer, A. (1992). Exploring the second language learner lexicon. In L. Verhoeven and J.H.A.L.de Jong (Eds.). The Construct of Language Proficiency. Amsterdam: John Benjamins. 147-162.

[10] Zhang Dexin. (2000). Reflections and Thoughts on Teaching Chinese as a Second Language (TCSL). Beijing: Foreign Language Teaching and Research Press.

[11] Zhou Jian. (2006). The Law of Chinese Characters. Beijing: People's Education Press.

Wenjie Dai was born in Qingdao, China in 1970. She received her M.A. degree in linguistics from The Ocean University of China in 2005 .

She is currently an associate professor in the International College of Qingdao University of Science and Technology, China. Her research interests mainly include language teaching and cultural comparison. 